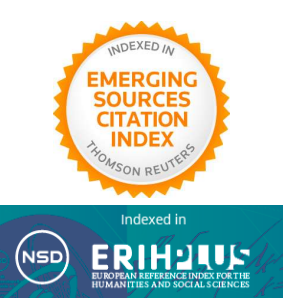

\title{
The intercultural dimension of English as an Academic Lingua Franca (EALF) in scientific publications
}

\author{
Richard Clouet ${ }^{1}$ \\ University of Las Palmas de Gran Canaria
}

\begin{abstract}
The objective of this paper is, on the one hand, to present and highlight the importance of intercultural communicative competence (ICC) in the use of academic English within a scientific environment and, on the other, to provide insights into understanding the disadvantage that non-native English-speaking scholars experience in international publishing. This paper begins by highlighting the importance of developing awareness of intercultural competency and sensitivity in academic writing and concludes by pointing out the need for increased understanding and tolerance on behalf of the editors and peer-reviewers of international academic journals. It emphasizes the need to promote acceptability and intelligibility, rather than mere conformity to the norms of the standard language, and it humbly aims at shifting long-established perceptions in the academic community.
\end{abstract}

Keywords: English as a lingua franca, English for academic purposes, interculturality, academia, publications

\section{RESUMEN}

El objetivo de este trabajo es, por un lado, presentar y poner de relieve la importancia de la competencia comunicativa intercultural en el uso de inglés académico dentro de un entorno científico y, por otro, indagar sobre las desventajas que tienen los investigadores no nativos a la hora de publicar sus artículos en inglés en revistas internacionales. Este artículo empieza por subrayar la importancia del desarrollo de una conciencia comunicativa y una sensibilidad intercultural en el entorno académico y concluye señalando la necesidad de aumentar la comprensión y la tolerancia por parte de los editores y revisores de revistas

1 Corresponding author - Facultad de Traducción e Interpretación. Campus Universitario del Obelisco. C/ Pérez del Toro 1, 35003. Universidad de Las Palmas de Gran Canaria (España).

Email: richard.clouet@ulpgc.es 
académicas internacionales. Se hace hincapié en la necesidad de promover los conceptos de aceptación e inteligibilidad, en lugar de la simple conformidad con las normas de la lengua estándar, y se pretende cambiar ciertas las percepciones establecidas desde hace tiempo en la comunidad académica.

Palabras clave: Inglés como lingua franca, Inglés para fines académicos, interculturalidad, academia, publicaciones

\section{Introduction}

The use of English as the lingua franca of the academic community in a variety of specialized fields such as medicine, engineering, science or business, only to quote a few, occurs in an international context that transcends the framework of national cultures to become a vehicle of intercultural communication. Furthermore, academic English itself is a product of intercultural communication, its characteristic linguistic features and conventions emerging directly from the very communication needs of the academic community over the last fifty years. As such, the academic language is used by and within a shared professional culture that transcends national cultures and can serve as a binding force.

Though back in 1974 Allen and Widdowson already argued the existence of a universal academic discourse, not much has been written about the hypothesis of a global academic culture linked with the concept of a discourse community, as developed by Swales (1990). The definition of the communication needs and attitudes of this discourse community of users of English for academic purposes is conditioned, to a certain extent, by two mainfactors: on the one hand, the intercultural dimension of academic discourse and, on the other, the dominance of English as the lingua franca of the international academic community.

Finally, this paper will discuss some language planning interventions aimed at developing the intercultural communicative competence of non-native users of English for academic purposes, bearing in mind that the ultimate objective of scientific publication is to share research results with other academics from all over the world successfully and effectively.

\section{Defining concepts: from ELF and EAP to EALF}

Language is the most important means of communication. Not only do people use language to talk about a variety of things and describe what they perceive, but they also do so to interact with other members of their community, share experiences and ideas. Therefore, when we talk about language teaching, we mean developing learners' communicative ability in real-life situations to efficiently express what they 
mean in the target language and successfully achieve communication in real-life situations (Lightbown and Spada, 2013). This success will mostly depend on social interaction driven by social needs of communication. Referring to the purpose of this paper, the sharing of research results among academics will be successful depending on the overall extent of dissemination and use of research findings within the scientific community. Indeed, the usefulness of scientific knowledge is limited if that knowledge is not communicated to other people in peer-reviewed journals that can be read by other scientists, at national and international conferences where other academics can listen to presentations, or in popular media, such as magazines, newspapers, and blogs. And they will mostly do so in English, the lingua franca par excellence.

The dominance of English as the lingua franca (ELF) of the academic community is a key issue. Allen and Widdowson (1974) were amongst the first scholars to question the support for a single language for scientific communication and to raise the problem of monolingualism in academia. Ever since the dominance of English in scientific publication and academic exchange has been raised by many (Ammon, 1990; Bidlake, 2008; Canagarajah, 1996; Curry and Lillis, 2004; Tardy, 2004; Wood, 1997), each reviewing its advantages and disadvantages, its points of interest and limitations. Wood (1997) even wonders whether scientific English is now the property of native speakers or of the international scientific community as a whole.

The phrase "Publish in English or perish!" was coined very early (Ventola, 1992) to describe the pressure in the scientific community to publish academic work in English, with the perception that scholars who publish in other languages may not gain the international recognition they deserve. The majority of high-impact journals are published in English and the non-English language journals that wish to compete in the world of academia and reach a wider audience are transitioning to English publications. Most international conferences are also held in English and the professional activity of academics is now often determined by their English language competence, not only in the field of research, but also as far as teaching and even administrative purposes are concerned.

The dominant position of English in academic communication as the language of publication and knowledge sharing, as well as the increasing use of English as the language of instruction have contributed to a growing interest in the field of English for academic purposes (EAP) (Ferguson, 2007) and, within EAP, to English for Research Publication Purposes (ERPP). When defining EAP, Björkman (2011: 81-83) makes a difference between English for foreign students studying in Englishspeaking countries (e.g. French students studying in the UK) and English students studying outside English-speaking countries (e.g. Spanish students studying English in Spain). While the former group may use both receptive and productive skills on a 
daily basis, the latter one will primarily use English in writing and reading. The same applies to scholars: those working in non-English-speaking countries are more likely to use English effectively in writing and reading, though the need to share their findings with other members of the scientific community in international encounters may also lead them to consider the necessity of using ELF as a medium of spoken interaction.

\begin{abstract}
It seems almost self-evident that the native speakers of the prevalent scientific language have less difficulty using it passively (in reading, oral understanding) and actively (in writing or speaking) than do non-native or foreign-language speakers and, therefore, have advantages over the latter in communicative situations which require the use of English. It is easier for them to produce utterances and text in line with existing, native-speaker norms. (Ammon, 2001: vii)
\end{abstract}

It seems more than obvious that working in English as a non-native language influences foreign academics' performance and success when it comes to publishing their research. However, we do not want to fall into the too general and simplistic division "native speaker" vs. "non-native speaker" and agree with Hyland when he refers to the need to nuance "crude Native vs non-Native polarization" (2016: 59) in academic writing for publication, as it is widely known and accepted that many nonnative speakers may be as competent for academic writing as native speakers. Nativeness per se may not be be regarded as a 'safe passage' in academia. Even if writing in a foreign language may pose greater challenge, there are both advantages and disadvantages associated with being a non-native English-speaking academic, depending on the strategies deployed by individual to enhance their linguistic capital in the academic field. We may rather focus the bi-literate academic skills of researchers than on the notion of the privileged position of the native speaker. Nevertheless, it is also true that situations vary and it may not be the same to be a native English speaker at an English-speaking university, a non-native speaker of English at an English-speaking university, or a non-native speaker of English at a non-English-speaking university where the day-to-day language is another language.

This phenomenon has given rise to a third group of EAP speakers: those who speak English as a lingua franca in academic settings, which we may denominate EALF (English as an academic lingua franca). Research on EALF has covered many areas of interest including morphosyntactic and pragmatic issues (Björkman, 2011; Björkman, 2012; Bolton and Kuteeva, 2012; Haberland, 2011; Hynninen, 2011; Jenkins, 2011; Mauranen, 2007; Mortensen, 2008; Murata, 2014). All converge towards a tendency for EALF speakers to resort to explicit language structures and place communication effectiveness over correctness in order to make themselves understood by academics of a variety of linguistic and cultural backgrounds. 
English has thus become a language that enables its users, native and non-native speakers from a variety of L1 backgrounds, to communicate across cultures. As Jenkins (2004) suggests, there are two categories of learners/users of English: those who learn English in order to be able to communicate with native speakers, their objective in learning the language being to speak like native speakers; and those who learn English primarily to communicate with non-native speakers, their main objective being to communicate successfully. Nowadays, the number of non-native speakers of English is far higher than that of native speakers, hence the importance of rethinking a series of aspects in the use of English for academic purposes, such as intelligibility, acceptability and intercultural communication.

I understand by intelligibility the successful achievement of mutual understanding by the people participating in a situation of written or spoken interaction, in other words the extent to which the participants establish mutual intelligibility in the interaction when collaboratively engaging in communication. This means that the conceptions of correctness in English as a lingua franca (ELF) may have nothing to do with the conceptions of correctness in English as a foreign language (EFL). Even though ELF speakers may differ in their use of linguistic resources, they are not necessarily assumed to be deficient communicators. Findings from ELF research suggest that "the main consideration [of speakers of ELF] is not formal correctness but functional effectiveness" (Hulmbauer et al., 2008: 28). While formal correctness has not been demonstrated to be a prerequisite for successful communication in ELF, mutual understanding and intelligibility have, participants in the interaction being motivated by a need to produce intelligible and comprehensible rather than native-speaker-like discourse. This explains why Jenkins points out that "there is really no justification for doggedly persisting in referring to an item as 'an error' if the vast majority of the world's English speakers produce and understand it" Jenkins, 2000: 160).

As such, I understand that the objective of academics should be to become pragmatically effective writers or speakers. They need to be able to use the appropriate pragmatic strategies to compensate for a lack of correctness and convey their message to their readers or listeners effectively. Björkman argues that "being proficient in the language does not presuppose that one is also a pragmatically effective speaker. In settings where English is used as a vehicular language, communicative effectiveness takes precedence over accuracy, fluency and language complexity" (Björkman, 2011: 85). Even if Björkman only refers to spoken interaction, I consider the same applies to written interaction, though it may be necessary to clarify that high-impact journals are expected to preserve the good use of the English language and inappropriate forms may not be accepted (Flowerdew, 2015). Certainly, greater quality means greater credibility (Bocanegra-Valle, 2014), 
but we may also believe that there is not always a clear correlation of language features with performance or academic attainment. Some areas of study like mathematics, medicine or engineering seem to give more importance to intelligibility than proficiency, an aspect which, as suggested by Flowerdew (2008), may be worth extending to the whole scientific community. Shouldn't the intelligibility of the community that a researcher belongs to, rather than standard English, be taken into consideration when deciding whether or not a paper is acceptable (Cho, 2009)?

However, generally speaking, publishing in English "has widely been reported as representing an additional hurdle" by non-English speaking scholars, "especially for those who have low proficiency levels in English language skills" (Martin, Rey-Rocha, Burgess and Moreno, 2014: 58). The majority confess to an added workload and often need assistance with their academic English. In the meantime, though recent research on EALF shows a clear tendency for non-English-speaking scholars to prioritize communication effectiveness over correction, the editors and reviewers of the international English-speaking community seem to have a bias against nonnative speakers of English (Cho, 2009), and consequently perceive EALF to be a threat to the English language itself, giving preference to "standard English", or "good English" over "lingua franca English" (Bocanegra-Valle, 2014: 73). Flowerdew (2008) claims that the intelligibility of the community that a researcher belongs to, rather than "standard English", should be taken into consideration when deciding whether or not a paper should be published.

A final aspect that seems to be necessary to discuss in the transition between ELF/EAP to EALF is what we understand by "good English". Greenbaum (1996: 17) makes a difference between "good English" and "correct English", clarifying that "correct English is conformity to the norms of the standard language" while "good English is a good use of the resources available in the language". He suggests that people with lower levels of proficiency might be able to speak good English. This corroborates Björkman's study (2011) in which the examination of a large corpus of spoken discourse showed that speakers with less proficiency were able to use the language effectively. Björkman's primary concern was spoken discourse, but it would certainly be worth carrying on studying a set corpus of written materials to see if this also applies to academic paper writing.

By no means do we assume that correctness is irrelevant in academic writing. Accuracy in form and grammar cannot be neglected; however contextual factors should be taken into account. Editors and reviewers should not forget that nonEnglish-speaking scholars are not only linguistically, but also socially and culturally different from mainstream academic language and discourse, hence the approach of this paper: editors of scholarly scientific research journals must not 
underestimate the intercultural dimension of English for academic purposes. They should take a pragmatic approach when reviewing the work of these scholars and shift the focus from language form and correctness to language use in a meaningful context.

\section{EALF and intercultural understanding}

I fully sympathize with Bidlake's argument (2008: 4) that "to insist on referring to [the non-native English-speaking scholars] as lacking is to occlude the reality that they are English users in their own right, and are working within a multilingual, multicompetent framework above and beyond the model of the monolingual native Englishspeaker", to which I would however add the adjectives "multi-cultural" and "intercultural". With this in mind, editorial boards should be more linguistically openminded and sympathetic to these scholars who constantly face the challenges of writing in English in order to ensure that their articles conform to native-Englishspeaker standards.

The vast majority of researchers in the field of language and culture teaching seem to have agreed over the last few years that what should be taught in the language classroom is the international culture (McKay, 2003), thus challenging and moving away from the traditional assumption that learners need to strive for standard English and for the values and behaviours of native speakers of English. McKay (2003) highlights the need to use material that fosters interaction between both native and non-native speakers in cross-cultural encounters as a way to exemplify the manner in which bilingual users of English are effectively using English to communicate for international purposes. Why should this not be applied to the field of academic English within a scientific environment? Do scientific publications not exemplify perfectly how English today serves a great variety of international purposes in a determined context? In a global world where most people learn English as a lingua franca, English teachers are being made aware of the importance of themselves as trained local non-native teachers who know that teaching pronunciation and culture should also be based on international standards, not only the native-speaker norms. What about editors and reviewers then?

Still referring to the field of teaching, when talking about teaching languages for academic purposes, we generally stress the importance of developing a communicative competence within academic contexts. Therefore, the studies on intercultural communication and cultural factors acquire a special relevance to which academia and editorial boards should not turn a deaf ear. This is particularly what the Modularising Multilingual and Multicultural Academic Communication Competence (MAGICC) project intended to do. The general objective of this project 
of the EU Lifelong Learning Programme (2011-2014) was "to integrate multilingual and multicultural academic communication competences as graduate learning outcomes at BA and MA level" (MAGICC web site: www.unil.ch/magicc/home). The MAGICC project was principally aimed at higher education students and teaching staff, but if we consider that it described and conceptualised multilingual and multicultural communication competences at MA level, then, to some extent, PhD students, who would be expected to write and publish papers, are expected to have reached the competences described by MAGICC and, as such, should have acquired the necessary tools for integrating academic and intercultural dimensions in their multilingual repertoire. This aspect should be rendered visible to third parties, as the project states, e.g. to editorial boards that should become more receptive to interculturality.

A language reflects a culture and culture shapes the language of a given community. In the case of the scientific community, it is essential to develop intercultural sensitivity that facilitates the understanding of values and ways of doing, interacting and addressing problems. However, culture is a complex concept which includes several aspects that can be approached from a variety of perspectives: local culture, personal culture, national culture, professional culture, the culture of individual organizations and institutions, etc. and all the aspects that underlie their external manifestations. From the perspective of the academic culture, intercultural communication should be based on the recognition that distinct cultures converge and merge in scientific journals, as many scholars have to negotiate various aspects of their own language and culture, the target language and culture, and each other's language and culture.

The development of intercultural awareness in a specific academic environment is certainly determined by the needs of the scientific community belonging to it and its extralinguistic characteristics: academic conventions, characteristic institutions and the very concept of knowledge. In our ever globalizing world in which English has become a key factor for success in academia, the scientific community has become "a space of intercultural import-export and of transculturation" (Singh and Doherty, 2004: 4), this being its major characteristic and determining the way knowledge is disseminated. Academia is seen as an intercultural discourse community in which members work together to establish intercultural relationship through the transmission and exchange of knowledge.

Fundamental to this is the notion of identity based on the grounds that people belong to a particular group and share a language. Ideally, this identity should be coconstructed by participants belonging to both sides of academia, English native speakers and non-English native speakers alike, thus leading to shifts in perceptions, changes and transformations on both sides. Without such shifts, non-native 
speakers of English will still be considered to be at a disadvantage when it comes to publishing their work in high-impact journals. Making things change seems to require a lot of institutional backing, collaboration, and people ready to champion the approach on all sides to get this into effective operation: EAP teachers, peerreviewers and editors. It is rather interesting to note two major inconsistencies in that respect: one the one hand, many scholars who are responsible for planning EAP courses, setting the objectives of such courses and teaching them are also members of editorial boards and often act as peer-reviewers in academic journals; on the other hand, for the last decade or so, the big publishers have jumped on the EAP bandwagon, advocating the need to focus on who the users of EAP are and what they need and want, and simultaneously publishing a wide range of academic journals where requirements concerning academic writing only abide by the norms of standard English. Would there not be a need to maximize coherence and transparency?

\section{EALF and intercultural rhetoric}

The development of intercultural awareness is closely linked to the definition of the speakers or writers' needs in a particular community and to how they construct multiple meanings of culture, cultural difference, and cultural identity. Furthermore, in order for academia to achieve cross-cultural understanding and to develop intercultural relationships between members of the scientific community, all parties must be made aware of the peculiarities displayed by non-native users of EAP when putting their research down on paper. The academic language used by e.g. German, Spanish or Korean scholars has particular discursive and rhetorical features that are directly related to a series of historical and cultural circumstances in which this academic language and culture have evolved. This is reflected in the discursive conventions of each language that make texts acceptable and are behind the genres and forms of expression of a particular discourse community. Translation Studies, Contrastive Rhetoric and more recently Intercultural Rhetoric have contributed to important advances in this issue.

Contrastive rhetoric started in 1966 with Kaplan's original examination of similarities and differences in writing across cultures in terms of cultural and rhetorical patterns, and was initiated by studies in second language writing, which identified problems foreign students had when writing in English. Writing about Kaplan's attention to cultural differences in the writing of English as a second language (ESL) students for academic purposes at US universities, Connor and Rozycki explain that:

Kaplan's observations about ESL students' paragraph writing pioneered attention to cultural differences in the writing of ESL students [...]. Kaplan 
analyzed essays written in English by students with a variety of first language backgrounds and showed that there was negative transfer from the first language writing to these second language essays [...]. Kaplan showed how differences from English in these second language writing patterns can be linked to how a school essay is organized in other languages such as Arabic, Chinese, Russian and Thai. (Connor and Rozycki, 2013: 428)

Since Kaplan's first publication, many researchers across the world have studied and contrasted writing patterns and styles in various languages and cultures, and written about the differences between non-native and native English students in rhetorical conventions across languages and cultures. Intercultural rhetoric started drawing on research carried out in contrastive rhetoric and gradually broadened the contrastive rhetorical study into different genres (Connor, 2004). Ever since, many intercultural rhetorical analyses have aimed at showing differences in the expression of interpersonal values in academic writing by contrasting several languages, i.e. between English and Spanish (Lorés-Sanz, 2009; Martín Martín, 2005; Mur-Dueñas, 2011; Pérez-Llantada, 2012), English and French (Swales and Van Bonn, 2007), English and Italian (Bondi, 2009; Molino, 2010), or English and Finnish (Ventola, 1992; Mauranen, 1993), only to quote a few. All such studies have investigated the differences between discursive styles due to distinctive cultural traditions, how these styles affect academic and scientific writing and the disadvantages they cause when writing in a foreign language. Discursive styles are different and speakers of other languages, even with a very high command of the grammar and vocabulary, always tend to transfer the discursive features of their own language. Asian scholars, for instance, have different ways of developing arguments that may look less structured and consistent to an English reader. German and Spanish academics do not seem to follow a linear structure, as their English counterparts would do, and German and Spanish texts resort to less explicit language than English ones.

Scollon and Scollon (1995) reflected on the singular rise of English scientific discourse in the eighteenth centuries as the expression of a communication philosophy in which all information should be conveyed as clearly, briefly and sincerely as possible (the C-B-S pattern), a utilitarian style of communication (Scollon and Scollon, 1995: 101-102) fostered by the Royal Society of London and "now widely seen as the norm in contemporary academic and professional communication of all kinds" (Scollon and Scollon, 1995: 69). According to Scollon and Scollon, "within this system there is a reinforced emphasis on direct talk, on avoiding elaboration and extravagance, and on promoting close, egalitarian social relationships" (Scollon and Scollon, 1995: 114-115). When identifying the main characteristics of English discourse, they highlight that it is interactive, public, based on knowledge, a clear sense of purpose and a clear linear pattern (Scollon and Scollon,1995: 107). All these principles are clearly reflected nowadays in handbooks on writing, style books and 
publication manuals.

The singular nature of English scientific and academic discourse and the discursive features of e.g. German or Spanish show evidence that there is not one universal academic discourse, contrary to what Gallego Mayordomo (2002) asserts in a study on the intercultural dimension of the academic language. In my opinion, Gallego Mayordomo wrongly bases the idea of a universal or global academic discourse on the concept of the discursive community developed by Swales (1990), forgetting that the latter carries out his studies within the framework of genre analysis. Swales uses a more restrictive approach and describes the discursive and argumentative strategies belonging to specific genres within the academic community. Gallego Mayordomo, however, seems to confuse the terms "global" and "intercultural". The scientific community is certainly universal since it is governed by the need to share common knowledge, to contribute to it and widen it. However, it is not necessary to conduct an empirical study to prove something most scholars have experienced: though mathematicians and linguists all belong to the same global academic community, it is quite obvious that the content, the supposedly standardized norms, as well as the discursive and argumentative strategies of the community of mathematicians, will not help the linguistic scholars understand the ideas their fellow researchers want to convey.

In the same way as nobody would ever consider altering the idiosyncrasy of mathematicians so that they can be more easily understood by other nonmathematician scholars, non-native English-speaking scholars should not be expected to forget their idiosyncrasy and tamed to neutralize the characteristics of their linguistic culture. Editors should thus remember that the features of English academic discourse are not those reflected in any particular country or culture. This language, which I earlier called EALF, is merely a vehicle for the communication needs of the community of scholars.

EALP has acquired such an intercultural dimension that it might be considered more productive to envisage the future of EALP from the angle of intercultural aspects. Beyond each scholar's immediate cultural context, the intercultural space has turned into the common space shared by all those who wish to publish their work in English.

\section{Implications}

The motivation for this study emerges from my experience as a non-native Englishspeaking scholar when it comes to publishing my research in international English language journals. As with most scholars of my kind, I have been faced with two 
major obstacles: (1) writing in English is cognitively more demanding for non-native speakers than for native-speakers and, consequently, more time-consuming; (2) neutralizing the characteristics of one's own linguistic culture in order to use the appropriate rhetorical style of the English language research community is an impediment.

As a non-English speaking author, I must admit I have often been faced with a fear of the potential bias towards manuscript submission and, when reading the instructions scientific journals give to their potential contributors, I have been concerned with questions related to how non-native English-speaking scholars can manage to represent their distinct cultures in English in an academic setting.

When reviewing the instructions for contributors published by leading international journals in a variety of fields, we soon come to the conclusion that their language policy is seldom made clear to authors. In the field of sciences, for instance, the International Journal of Computational Methods, published by World Scientific Publishing, only states that "the manuscript must be original and written in English". Following the same line, the International Journal of Biomedical Engineering and Technology, published by Inderscience Publishers, stresses the fact that "All articles must be written in UK English. If English is not your first language, please ask an English-speaking colleague to proofread your article".

Resorting to the help of English-speaking colleagues, certainly to be understood as English-native-speaking colleagues, is common to most guidelines. The editors of the International Journal of Speech Technology, published by Springer, insist on the importance of using standard English if authors want their papers to go through the peer-review process successfully:

\begin{abstract}
Manuscripts that are accepted for publication will be checked by our copyeditors for spelling and formal style. This may not be sufficient if English is not your native language and substantial editing would be required. In that case, you may want to have your manuscript edited by a native speaker prior to submission. A clear and concise language will help editors and reviewers concentrate on the scientific content of your paper and thus smooth the peer review process.
\end{abstract}

Success is at the heart of the International Journal of Medical Sciences publishing policy and Ivyspring International Publisher warns that "manuscripts that are judged to be of insufficient quality or unlikely to be competitive enough for publication will be rejected during initial screening". In order for research papers to contribute to the success of their authors, the International Journal of Mathematics and Mathematical Sciences, published by Hindawi, adds that "all manuscripts are subject to peer review and are expected to meet standards of academic excellence". 
In some cases, to render the work of non-English native scholars even more difficult, a "British English only" policy might be observed, as in the International Journal of Regional and Local History, published by Routledge: "Please note that this journal only publishes manuscripts in English [...]. Please British spelling consistently throughout the manuscript".

We might expect journals publishing articles related to the humanities, generally speaking, and particularly to language and cultural studies, to be more open-minded and interculturally sensitive. Their main consideration, however, is still on formal correctness rather than functional effectiveness, with instructions insisting on native speaking models and giving unfair advantage to English native-speaking academics. The International Journal of Corpus Linguistics, published by John Benjamins Publishing, emphasises that "contributions are to be in English. If not written by a native speaker, it is strongly advised to have the paper checked by a native speaker. Spelling should be British English or American English and should be consistent throughout the paper". In the same line of thought, the International Journal of Language and Culture, also published by John Benjamins Publishing, reminds authors that "if [they] are not native speakers of the language in which [they] have written [their] contribution, it is advised to have [their] text checked by a native speaker".

Unfairness reaches a critical level when contributors are encouraged to pay for the services of editing consultants, inferring that English's dominance as the language of science puts non-native speakers at a disadvantage from the start. Oxford University Press, Cambridge University Press, Sage and Elsevier, only to quote a few, all give the same recommendations. The ELT Journal, published by Oxford University Press, advises that authors whose "first language is not English" resort to language editing, even if they add that it "does not guarantee that [their] manuscript will be accepted for publication". The Journal of English Linguistics (ENG), published by Sage, suggests that "authors who would like to refine the use of English in their manuscripts might consider using the services of a professional English-language editing company". The International Journal of Asian Studies, as well as most journals published by Cambridge University Press, recommends that "authors have their manuscripts checked by an English language native speaker before submission; this will ensure that submissions are judged at peer review exclusively on academic merit". Finally, the Journal of English for Academic Purposes, the Journal of English for Specific Purposes, the International Journal of Intercultural Relations, all published by Elsevier, give the same advice to non-English native-speaking authors, even if they do not explicitly use the expression "non-native":

Please write your text in good English (American or British usage is accepted, but not a mixture of these). Authors who feel their English language manuscript may require editing to eliminate possible grammatical or 
spelling errors and to conform to correct scientific English may wish to use the English Language Editing service available from Elsevier's WebShop or visit our customer support site for more information.

Language editing has clearly become a lucrative business, each publisher offering a list of specialist language editing companies, though clarifying that the use of these services is voluntary and at the author's own expense, and even, in the case of Sage, that it "has no affiliation with these companies and makes no endorsement of them".

The main consideration of all the guidelines mentioned above is that their ultimate objective is to bring papers to a publishable standard, generally placing, at least explicitly, formal correctness above functional effectiveness. Unwillingly, by stressing the importance of getting help from native speakers, they highlight the perception of disadvantage on behalf of the non-native English-speaking researchers who will see their non-native speaker status as an additional burden.

Of note here, and encouraging for the purpose of the present study, is the guide for authors issued by De Gruyter for authors who wish to publish their work in the Journal of English as a Lingua Franca (JELF), published by De Gruyter. It is the only journal whose website I have consulted that explicitly states that:

Authors should follow the De Gruyter Mouton style sheet but with one change: While the standard style sheet stipulates, under 'Special attention', that authors should have their "contribution carefully checked by a native speaker", the editors of JELF simply expect authors to submit manuscripts written in an English which is intelligible to a wide international academic audience, but it need not conform to native English norms.

Though logically recognising the linguistic inequality between native and non-native speakers, their guidelines seem to be designed to mitigate such disadvantage and encourage non-native academic efforts to publish in a high-impact journal.

This goes along with an increasing awareness of what editorial boards might consider taking into account in the future and reinforces the point I have intended to make in this paper. Editors, as part of the intercultural discourse community of scholars, may grant the necessity of incorporating the following aspects in their guidelines for authors and peer-reviewers:

- Cultural diversity should be valued as an asset in international publications and the appraisal of contextual factors should be seen as a way of enriching intercultural understanding. Although the linguistic/cultural context may affect especially the rhetorical organization of a paper, it also contributes to augment intercultural communication and widens the range of experiences and views from different 
sides and perspectives of the academic community. Intercultural communication is about developing the ability to identify and challenge editors and peerreviewers' cultural assumptions, their values and beliefs, and developing empathy and shared knowledge". Intercultural communication requires the ability to see the world through different cultural lenses; it encourages critical and reflective approaches and avoids the on-track approach and single mind-set.

- Intelligibility should be valued over perfect accuracy, seeing in intelligibility the successful achievement of mutual understanding in an intercultural communication environment. Awareness should be raised as to the fact that the conceptions of correctness in English as an academic lingua franca (EALF) may have nothing to do with the conceptions of correctness in English as a foreign language (EFL) and may differ from the so-called standards of English for academic purposes (EAP). Linguistic norms for journal submissions may be relaxed, as advocated by Ammon $(2000,2006)$, which could represent a further step toward the establishment of an alternative set of EALF norms that Ammon (2006) refers to as 'globalish'.

- Finally, journals may provide contributors with explicit instructions on the rhetorical options available and the implications of taking them, so that they can appeal to readers from within the boundaries of their discipline (Hyland, 2008). Such instructions should highlight the criterion of clarity and intelligibility as and quality as a key requisite to reach success and increase the visibility of their work.

Obviously, my purpose is not to imply that correctness is totally irrelevant. Grammatical accuracy is of utmost importance. However, I would suggest to editorial boards that, in EALF settings where scholars are from a range of levels of proficiency, both non-native speakers and their English-native-speaking colleagues should be treated on the same footing provided that their papers are comprehensible to the wider academic community.

\section{Planning intervention}

In order to help reduce the gap between native and non-native speakers of English, I would suggest that they should be trained together within the same discourse community. Intercultural communication between native and non-native writers can but benefit both in order to become more performant.

Because they belong to the same discourse community, people share some kind of activity, common goals, a common purpose and consequently have their own particular ways of communicating, of exchanging information with each other, of using specialised terminology and vocabulary. In other words, they have their own genres and are expected to have a high level of expertise in using these genres. In the case of writing, whether they write in their native language or in a second 
language, academics are involved in a common activity and can only benefit from each other in order to improve their discourse.

As a result, the two issues we have addressed in this article - that of the use of English by academics and that of teaching the use of English within academia - may come together, as native writers of English can serve as models to non-native writers who belong to the same discourse community, helping them to identify the main rhetorical stages in the text, highlighting the social and cultural context in which a text occurs, stressing the importance of aim and purpose, and discussing the analysis of simple texts. Comparing each other's texts, carrying out peer-revision or editing texts would strongly contribute to improvements in non-native teachers' writing skills. The latters would feel supported by the members of their discourse community and gradually guided towards more autonomy.

Comparing texts written by members of the same discourse community should be seen as a useful strategy, whether the comparison is based on some set of guidelines, such as a list of key aspects of language and discourse, or on general observations about thematic progression, patterns of cohesion and coherence, or rhetorical analysis. In this approach, non-native writers work with "apprentice" exemplars rather than expert models and consequently feel more motivated when their work is assessed.

Peer-reading and peer-reviewing may also help enhancing the importance of and awareness about the intercultural content. For instance, critical reading may reinforce writers, both native and non-native, to analyse how texts are written, how the topic is exposed, what type of genre is used, how the content can vary according to the culture, and will surely help non-native academic to better understand the reports sent by peer-reviewers and editors, but also peer-reviewers to better understand to what extent culture shapes the language of a given community.

The idea behind all this is to create a strong felling of scientific community in which the members display multiple cultures and cultural identities that need to be taken into account when it comes to assessing their work. This point of view is shared by Brian Paltridge in his latest book The discourse of peer review. Reviewing submissions to academic journals. He suggests ways in which the analysis of several reviews (reviews of book proposals, reviewers' reports on submissions to peer-reviewed journals, etc.) can be taken up in reviewer training and academic writing development courses, fostering a 'learning by doing' approach rather than a strictly didactic one.

\section{Conclusions}

In the first part of this paper, I have considered the dominant position of English in 
academic communication as the language of publication and researched into the intercultural dimension of the academic community; a community in which the speakers and writers display multiple cultures and cultural identities.

Following this analysis, I have discussed certain concepts, such as those of contrastive cultural analysis and conflicting discourses, as possibilities for intercultural learning, but also encouraged the editorial boards of academic journals to become spaces for international scholars to achieve their goals through successful cross-cultural understanding and intercultural sensitivity. I have advocated a pragmatic approach at the centre of which we should place intercultural sensitivity (to facilitate understanding of values and ways of doing, interacting and to address problems) and flexibility (to adapt to cultural differences) by permitting the publication of papers written in comprehensible rather than perfect English, of which there are several variants even amongst native English speakers.

However, aware of the challenges met by non-native English-speaking scholars when trying to get their work published, I strongly believe that future research in the intercultural dimension of English for academic purposes should focus on, on the one hand, the genres produced by academics, such as research articles, conference papers, etc. and, on the other hand, the analysis of peer-reviewing processes and feedback provision. Quoting Ulla Connor:

\footnotetext{
Not only do we need to learn more about specific linguistic and textual features of these genres, but we also need to learn more about the contexts and processes of producing them. This means that, in addition to the published texts themselves, we need, for example, to study and understand draft revisions, correspondence with editors and reviewers, negotiations among co-authors. (Connor, 2013: 425)
}

Studying the reports sent by peer-reviewers and editors will be invaluable to improve understanding between the different parties and equip non-native Englishspeaking scholars with the appropriate tools to meet the requirements of editorial boards and to be able to publish their work successfully. All this would help both scholars and editors define the standards of use for EALF from an intercultural communication perspective. It would also serve to establish how much variation from the standard language can be tolerated within this particular discourse community. 


\section{About the author}

Richard Clouet, PhD, is a Lecturer in the Department of Modern Languages (Faculty of Translation and Interpreting) at the University of Las Palmas de Gran Canaria. He is a member of the research group FLETATIS (Foreign Language Education through Applied Technologies and Intercultural Sensitivity). His research fields include EFL acquisition in Translation studies, EAP, ELF and intercultural teaching/learning.

\section{Article history}

Paper received: 9th February 2017

Paper received in revised form and accepted for publication: 28th October 2017

\section{References}

Allen, J. P. B. \& Widdowson, H. G. (1994). Teaching the communicative use of English. International Review of Applied Linguistics, 12(1), 1-20.

Ammon, U. (2001). Editor's preface. In U. Ammon (Ed.), The dominance of English as a language of science (pp. v-xiv). Berlin \& New York: Mouton de Gruyter.

Ammon, U. (2006). Language planning for international scientific communication: an overview of questions and potential solutions. Current Issues in Language Planning, 7(1), 130.

Ammon, U. (2012). Linguistic inequality and its effects on participation in scientific discourse and on global knowledge accumulation - with a closer look at the problems of second-rank language communities. Applied Linguistics Review, 3(2), 333-355.

Ammon, U. (1990). German or English? The problems of language choice experienced by German-speaking scientists- In P. Nelde (Ed.), Plurilingua: Language Conflict and Minorities (pp. 33-52). Bonn: Dümmler.

Bidlake, E. (2008). Whose voice gets read? English as the international language of scientific publication. E-pesteme, 1(1), 3-21.

Björkman, B. (2011). English as a lingua franca in higher education: Implications for EAP. Ibérica, 22, 79-100.

Björkman, B. (2012). Questions in academic ELF interaction. Journal of English as a Lingua 
Franca, 1(1), 93-119.

Bocanegra-Valle, A. (2014). 'English is my default academic language': Voices from LSP scholars publishing in a multilingual journal. Journal of English for Academic Purposes, 13, 65-77.

Bolton, K. \& Kuteeva, M. (2012). English as an academic language at a Swedish university: parallel language and the 'threat' of English. Journal of Multilingual and Multicultural Development, 33(5), 429-447.

Bondi, M. (2009). Historians at work: reporting frameworks in English and Italian book review articles. In K. Hyland \& G. Diani (Eds.), Academic Evaluation: Review Genres in University Settings (pp. 179-196). Basingstoke: Palgrave MacMillan.

Canagarajah, A. S. (1996). 'Nondiscursive' requirements in academic publishing, material resources of periphery scholars, and the politics of knowledge production. Written Communication, 13(4), 435-473.

Canagarajah, A. S. (1999). Interrogating the 'native speaker fallacy': Non-linguistic roots, nonpedagogical results. In G. Braine (Ed.), Non-Native Educators in English Language Teaching (pp. 77-92). Mahwah, NJ: Lawrence Erlbaum.

Cho, D. W. (2009). Science journal paper writing in an EFL context: The case of Korea. English for Specific Purposes, 28(4), 230-239.

Connor, U. (2004). Intercultural rhetoric research: Beyond texts. Journal of English for Academic Purposes. Special Issue on Contrastive Rhetoric in EAP, 3(4), 291-304.

Connor, U. \& Rozycki, W. (2013). ESP and Intercultural Rhetoric. In B. Paltridge \& S. Starfield (Eds.), The Handbook of English for Specific Purposes (pp. 427-443). Chichester, UK: WileyBlackwell.

Curry, M. J. \& Lillis, T. M. (2004). Multilingual scholars and the imperative to publish in English: negotiating interests, demands, and rewards. TESOL Quarterly, 38(4), 663-688.

Ferguson, G. R. (2007). The global spread of English, scientific communication and ESP: questions of equity, access and domain loss. Ibérica, 13, 7-38.

Flowerdew, J. (2008). Scholarly writers who use English as an additional language: What can Goffman's 'Stigma' tell us? Journal of English for Academic Purposes, 7(1), 77-86.

Flowerdew, J. (2015). Some thoughts on English for Research Publication Purposes (ERPP) and related issues. Language Teaching, 48(2), 250-262.

Gallego Mayordomo, J. L. (2002). Dimensión intercultural del lenguaje académico y necesidades comunicativas en la enseñanza de EPFA (español para fines académicos). ASELE Actas XIII, 274-287.

Greenbaum, S. (1996). The Oxford English Grammar. Oxford: Oxford University Press.

Haberland, H. (2011). Ownership and maintenance of a language in transnational use: Should we leave our lingua franca alone? Journal of Pragmatics, 43, 937-949. 
Hulmbauer, C., Böhringer. H. \& Seidlhofer, B. (2008). Introducing English as a lingua franca (ELF): Precursor and partner in intercultural communication. Synergies Europe, 3, 25-36.

Hyland, K. (2008). Persuasion, interaction and the construction of knowledge: Representing self and others in research writing. International Journal of English Studies, 8(2), 1-23.

Hyland, K. (2016). Academic publishing and the myth of linguistic injustice. Journal of Second Language Writing, 31, 58-69.

Hynninen, N. (2011). The practice of 'mediation' in English as a lingua franca interaction. Journal of Pragmatics, 43, 965-977.

Jenkins, J. (2000). The Phonology of English as an International Language. Oxford: Oxford University Press.

Jenkins, J. (2007). English as a lingua franca: attitude and identity. New York: Oxford University Press.

Jenkins, J. (2005). ELF at the gate: the position of English as a Lingua Franca. Humanising Language Teaching, 7(2). <http://htlmag.co.ul/mar05/idea.htm> [01/03/2016].

Jenkins, J. (2011). Accommodating (to) ELF in the international university. Journal of Pragmatics, 43, 926-936.

Kaplan, R. B. (1966). Cultural thought patterns in intercultural education. Language Learning, $16,1-20$.

Lightbown, P. M. \& Spada, N. (2013). How Languages Are Learned. Oxford: Oxford University Press.

Lorés-Sanz, R. (2009). Different worlds, different audiences: a contrastive analysis of research article abstracts. In E. Suomela-Salmi \& F. Dervin (Eds.), Crosslinguistic and Cross-cultural Perspectives on Academic Discourse (pp. 187-197). Amsterdam \& Philadelphia: John Benjamins.

Martín Martín, P. (2005). The Rhetoric of the Abstract in English and Spanish Scientific Discourse: A Cross-cultural Genre-analytic Approach. Bern: Peter Lang.

Martín Martín, P., Rey-Rocha, J., Burgess, S. \& Moreno, A. I. (2014). Publishing research in English-language journals: Attitudes, strategies and difficulties of multilingual scholars of medicine. Journal of English for Academic Purposes, 16, 57-67.

Mauranen, A. (1993). Contrastive ESP rhetoric: metatext in Finnish-English economic texts. English for Specific Purposes, 12(3), 3-22.

Mauranen, A. (2007). Hybrid voices: English as the lingua franca of academics. In K. Flottum (Ed.), Language and Discipline Perspectives on Academic Discourse (pp. 243-259). Newcastle: Cambridge Scholars.

McKay, S. L. (2003). Reflections on being a gatekeeper. In C. P. Casanave \& S. Vandrick (Eds.), Writing for scholarly publication: Behind the scenes in language education (pp. 91-102). Mahwah, NJ: Lawrence Erlbaum Associates. 
Molino, A. (2010). Personal and impersonal authorial references: A contrastive study of English and Italian Linguistics research articles. Journal of English for Academic Purposes, 9, 86-101.

Mortensen, J. (2008). 'Circus English?' Investigating English as an academic lingua franca at BA study group meetings at Roskilde University. In H. Haberland, J. Mortensen, A. Fabricius, B. Preisler, K. Risager \& S. Kjaerbeck (Eds.), Higher Education in the Global Village (pp. 8596). Roskilde: Department of Culture and Identity.

Mur-Dueñas, P. (2011). An intercultural analysis of metadiscourse features in research articles written in English and in Spanish. Journal of Pragmatics, 43, 3068-3079.

Murata, K. (2014). English as a Lingua Franca in the International University: The Politics of Academic English Language Policy. ELT Journal, 68(2), 205-207.

Paltridge, B. (2017). The discourse of peer review. Reviewing submissions to academic journals. London: Palgrave Macmillan.

Pérez-Llantada, C. (2012). Scientific discourse and the rhetoric of globalization. The impact of culture and language. London: Bloomsbury.

Scollon, R. \& Scollon, S. W. (1995). Intercultural communication: a discourse approach. Malden, MA: Blackwell.

Singh, P. \& Doherty, C. A. (2004). Global cultural flows and pedagogical dilemmas: Teaching in the global university contact zone. TESOL Quarterly, 38(1), 9-42.

Snow, M. A., Kamhi-Stein, L. D. \& Brinton, D. M. (2006). Teacher Training for English as a Lingua Franca. Annual Review of Applied Linguistics, 26, 261-281.

Swales, J. M. (1990). Genre analysis: English in academic and research settings. Cambridge, UK: Cambridge University Press.

Swales, J. M. \& Van Bonn, S. (2007). Similarities and differences in French and English EAP research article abstracts: the case of ASP. In K. Fløttum (Ed.), Language and Discipline Perspectives on Academic Discourse (pp. 275-294). Newcastle upon Tyne: Cambridge Scholars Press.

Tardy, C. M. (2004). The role of English in scientific communication: lingua franca or Tyrannosaurus rex? Journal of English for Academic Purposes, 3(3), 247-269.

Ventola, E. (1992). Writing scientific English: overcoming intercultural problems. International Journal of Applied Linguistics, 2(2), 191-220.

Wood, A. (1997). International scientific English: some thoughts on science, language and ownership", Science Tribune. <http://www.tribunes.com/tribune/art97/wooda.htm> [07/03/2016]. 